\title{
Cerebral Energy Metabolism in Phenylketonuria: Findings by Quantitative In Vivo ${ }^{31} \mathrm{P}$ MR Spectroscopy
}

\author{
JOACHIM PIETZ, ANDRÉ RUPP, FRIEDRICH EBINGER, DIETZ RATING, ERTAN MAYATEPEK, \\ CHRIS BOESCH, AND ROLAND KREIS \\ Departments of Pediatric Neurology [J.P., A.R., F.E., D.R.] and General Pediatrics [E.M.], Division of \\ Metabolic and Endocrine Diseases, University Children's Hospital, Im Neuenheimer Feld, D-69120 \\ Heidelberg, Germany; and Department of Clinical Research [C.B., R.K.], Unit of Magnetic Resonance \\ Spectroscopy and Methodology, University of Berne, MR Center 1, CH-3010 Berne, Switzerland
}

\begin{tabular}{|c|c|}
\hline \multicolumn{2}{|c|}{ ABSTRACT } \\
\hline $\begin{array}{l}\text { Both severe impairments of brain development in untreated } \\
\text { infants and acute reversible neurotoxic effects on brain function } \\
\text { are clinical features of phenylketonuria (PKU). For determining } \\
\text { whether impairments of cerebral energy metabolism play a role } \\
\text { in the pathophysiology of PKU, quantitative in vivo }{ }^{31} \mathrm{P} \text { magnetic } \\
\text { resonance spectroscopy (MRS) was performed in a supratentorial } \\
\text { voxel of } 11 \text { adult PKU patients and controls. Peak areas of } \\
\text { inorganic phosphate; phosphocreatine; } \alpha-, \beta-\text {, and } \gamma \text {-ATP; NAD; } \\
\text { phosphomonoesters; phosphodiesters; and a broad phospholipid } \\
\text { signal were converted to millimolar concentrations. } \mathrm{Mg}^{2+} \text {, pH, } \\
\text { ADP, the phosphorylation potential, and the relative velocity of } \\
\text { oxidative metabolism V/V } \text { max were derived. Clinical evaluation } \\
\text { included mutation analysis, neurologic investigation, intelligence } \\
\text { testing, magnetic resonance imaging, and concurrent plasma and } \\
\text { brain phenylalanine (Phe), the last by }{ }^{1} \mathrm{H}-\mathrm{MRS} \text {. Phe loading was } \\
\text { performed in five patients with an oral dose of } 100 \text { mg/kg body } \\
\text { wt L-Phe monitored by spectral EEG analysis. Under steady- } \\
\text { state conditions, }{ }^{31} \mathrm{P}-\mathrm{MRS} \text { revealed normal values for ATP, } \\
\text { phosphocreatine, NAD, phosphomonoesters, phosphodiesters, } \\
\left.\text { Mg }{ }^{2+} \text {, and pH in PKU. ADP ( }+11 \%\right) \text { and the phosphorylation } \\
\text { potential ( } 22 \% \text { ) were increased. Peak areas of inorganic phos- } \\
\text { phate ( } 22 \%) \text { and phospholipid ( }-8 \% \text { ) were decreased. ADP } \\
\text { correlated with concurrent plasma ( } \mathrm{r}=0.65) \text { and brain ( } \mathrm{r}=0.55) \\
\text { Phe. During the Phe load, blood Phe levels increased steeply. }\end{array}$ & $\begin{array}{l}\text { EEG revealed slowing of background activity. The phosphory- } \\
\text { lation potential decreased, whereas ADP and } \mathrm{V} / \mathrm{V}_{\max } \text { increased. } \\
\text { In vivo }{ }^{31} \mathrm{P}-\mathrm{MRS} \text { demonstrated subtle abnormalities of cerebral } \\
\text { energy metabolism in PKU in steady-state conditions that were } \\
\text { accentuated by a Phe load, indicating a link between Phe neuro- } \\
\text { toxicity and imbalances of cerebral energy metabolism. (Pediatr } \\
\text { Res 53: 654-662, 2003) } \\
\quad \text { Abbreviations } \\
{ }^{1} \mathbf{H}-\mathbf{M R S} \text {, proton magnetic resonance spectroscopy } \\
\text { IDC, index of dietary control } \\
\text { MPF, mean power frequency } \\
\text { MRI, magnetic resonance imaging } \\
\text { P }_{\text {I }} \text { inorganic phosphate } \\
\text { PAH, phenylalanine hydroxylase } \\
\text { PCr, phosphocreatine } \\
\text { PDE, phosphodiesters } \\
\text { Phe, phenylalanine } \\
\text { PL, phospholipids } \\
\text { PME, phosphomonoesters } \\
\text { 31P-MRS, phosphorus-31 magnetic resonance spectroscopy } \\
\text { PKU, phenylketonuria } \\
\text { PP, phosphorylation potential }\end{array}$ \\
\hline
\end{tabular}

Phenylketonuria (PKU) is the most frequent inborn disorder of amino acid metabolism. PKU is caused by an autosomal recessively transmitted deficiency of hepatic phenylalanine (Phe) hydroxylase (PAH; enzyme commission 1.14.16.1). In

Received April 15, 2002; accepted October 2, 2002.

Correspondence: Joachim Pietz, M.D., Department of Pediatric Neurology, University of Heidelberg, Im Neuenheimer Feld 150, D-69120 Heidelberg, Germany; e-mail: joachim_pietz@med.uni-heidelberg.de

Supported by the Medical Faculty, University of Heidelberg (Project 351/2000) and the Swiss National Foundation (31-43280.95 and 31-59082.99).

DOI: 10.1203/01.PDR.0000055867.83310.9E untreated PKU patients, Phe accumulates to plasma levels exceeding $1500 \mu \mathrm{M}$; normal plasma Phe in fasting adults is $\sim 60 \mu \mathrm{M}$. The characteristics of untreated PKU result from disturbed brain development and include microcephaly, epilepsy, severe mental retardation, and behavior problems (1).

Through the early start of a Phe-restricted diet, the phenotype of untreated PKU can be widely prevented. However, elevated plasma concentrations of Phe, which usually occur in adolescence because of a relaxed diet, are known to cause acute impairments of brain function. Reduced attentional abilities, slow information processing, and typical changes in the 
spectral pattern of brain electrical activity (EEG) have been observed (2). Magnetic resonance imaging (MRI) revealed white matter abnormalities also in neurologically normal earlytreated patients (3).

Despite progress in the description of the molecular variability of PKU, the biochemical and cellular mechanisms underlying impaired brain development and cerebral dysfunction by acute Phe "toxicity" remain unclear. Besides several other important aspects, inhibition of enzymes involved in cerebral energy production has been shown for Phe in in vitro studies (4-7). However, no clear evidence could be established to prove that impaired cerebral energy metabolism represents a key explanatory factor for PKU-related brain damage or dysfunction in vivo (8).

Quantitative phosphorus-31 magnetic resonance spectroscopy $\left({ }^{31} \mathrm{P}-\mathrm{MRS}\right)$ can serve as a noninvasive tool for examination of energy status in vivo. This approach is routinely used to study muscle energetics $(9,10)$ but has also been used to investigate disturbances of brain function in many cerebral and metabolic diseases (11). The aim of the present study was to determine the concentrations of cerebral metabolites detected by ${ }^{31} \mathrm{P}-\mathrm{MRS}$ in early-treated PKU patients under steady-state conditions, to compare them with a control group, and to relate the results to blood and brain concentrations of Phe. In addition, ${ }^{31} \mathrm{P}-\mathrm{MRS}$ was done before and $24 \mathrm{~h}$ after an oral challenge with L-Phe, while brain activity was monitored using EEG spectral analysis (12).

\section{METHODS}

Patients and control subjects. Eleven early-treated patients with PKU (four women, seven men, mean age $24.9 \pm 3.9$ y) participated in this study. Diet onset ranged from 11 to $63 \mathrm{~d}$ (Table 1). ${ }^{31} \mathrm{P}$-MRS data from 10 healthy volunteers (five women, five men; $26.2 \pm 5.1 \mathrm{y}$ ) were acquired to define normal ranges. This study was approved by the Ethics Committee of the University of Heidelberg. Before the study, the experimental protocol was explained to all subjects and their written informed consent according to the declaration of Helsinki 1996 was obtained.

Laboratory and clinical examination. Plasma Phe concentrations concurrent with ${ }^{31} \mathrm{P}$-MRS were determined with an enzymatic assay (Quantase Phe assay, Porton Cambridge, UK). An index of dietary control (IDC) was derived from the patients' plasma Phe values from diet onset (Table 1) until the time of the study to characterize long-term biochemical control. Further clinical evaluation (Table 1) included the identification of PAH mutations. Mutations were classified according to Guldberg et al. (13). All patients were examined with a standardized neurologic investigation, standard MRI, and intelligence testing (Wechsler Adult Intelligence ScaleRevised). MRI-visible white matter abnormalities were graded according to the scheme described earlier (3).

For determining brain tissue concentrations of Phe, localized ${ }^{1} \mathrm{H}-\mathrm{MRS}$ was performed after the ${ }^{31} \mathrm{P}$-MRS session on the same scanner as described in detail elsewhere $(12,14,15)$. In brief, spectra were recorded from a large volume of $\sim 60 \mathrm{~cm}^{3}$ above the ventricular system involving white and gray matter using a spin-echo localization sequence (echo time $20 \mathrm{~ms}$, repetition period $3 \mathrm{~s}$ ). The full data processing scheme is detailed elsewhere (12).

${ }^{31} \boldsymbol{P}$-MRS. All ${ }^{31} \mathrm{P}$ MR spectra were recorded on a clinical MRI scanner (1.5T Signa, General Electric Medical Systems, Milwaukee, WI, U.S.A.) using a double-tuned bird cage ${ }^{1} \mathrm{H} /{ }^{31} \mathrm{P}$ head coil (quadrature for ${ }^{31} \mathrm{P}$, linear for ${ }^{1} \mathrm{H}$, GE Medical Systems). A supraventricular region of interest was selected using an ISIS sequence with adiabatic inversion, excitation, and saturation pulses (16). Nominal region of interest size was $70 \mathrm{~cm}^{3}$. Repetition time was $4.0 \mathrm{~s}$. Four spectra of 128 scans were acquired per subject. Total examination time was $75 \mathrm{~min}$. Absolute quantification was based on measurement of the local $\mathrm{B}_{1}$ field, the reciprocity principle, and calibration with solutions of known concentration, as well as constrained model fitting, as described in detail recently (17).

Intracellular $\mathrm{pH}$ was calculated from the chemical shift of inorganic phosphate $\left(P_{i}\right)$ in relation to phosphocreatine $(\mathrm{PCr})$ using the calibration of Petroff et al. (18). Free $\mathrm{Mg}^{2+}$ content was estimated from the frequency difference of $\beta$-ATP and PCr using the parameters of Iotti et al. (19). An overall cytosolic ADP concentration (20) was calculated on the basis of the creatine kinase equilibrium:

$$
[A D P]=\frac{[C r][A T P]}{K_{c k}[P C r][H]}
$$

where the in vitro value of $1.6610^{9} \mathrm{M}^{-1}$ is used for the creatine kinase equilibrium constant $K_{C K}(20,21)$. [Cr] is calculated from the measured $\mathrm{PCr}$ concentration, assuming a constant total creatine content of $6.3 \mathrm{mmol} / \mathrm{kg}_{\mathrm{ww}}(22)$, and $[H]$ is the proton concentration derived from the measured $\mathrm{pH}$ $\left(10^{-\mathrm{pH}} \mathrm{M}\right)$. The effective $K_{\mathrm{CK}}$ depends on local $\mathrm{pH}, \mathrm{Mg}^{2+}$, and $\mathrm{K}^{+}$contents, all of which can be assumed to be unchanged in PKU. For $\mathrm{pH}$ and $\mathrm{Mg}^{2+}$, this assumption is confirmed by the current results. For total creatine, no significant changes have been found for PKU in ${ }^{1} \mathrm{H}$-MRS studies. In addition, the phosphorylation potential (PP), an index of free available energy per ATP, was derived (21):

$$
P P=\frac{[A T P]}{[A D P][P i]} .
$$

The velocity of oxidative metabolism relative to its maximum $\left(V / V_{\max }\right)$ was calculated on the basis of a steady-state Michaelis-Menten formulation:

$$
V / V_{\max }=\frac{1}{1+0.02 /[A D P]+0.13 /[P i]},
$$

where $[A D P]$ and $\left[P_{i}\right]$ are in units of $\mathrm{mM}(23)$ such that $V / V_{\max }$ is dimensionless.

Oral load with L-phenylalanine in five patients. Five patients $(3,4,5,8$, and 11) underwent an oral challenge with L-Phe. They were administered a single oral dose of $100 \mathrm{mg}$ of purified L-Phe per kilogram of body weight. ${ }^{31} \mathrm{P}-\mathrm{MRS}$ was performed preload and $22 \mathrm{~h}$ postload. For detecting Phe-related changes of brain activity, EEG in the relaxed awake state with eyes closed were derived preload and $24 \mathrm{~h}$ postload. Electrodes 
PIETZ ET AL.

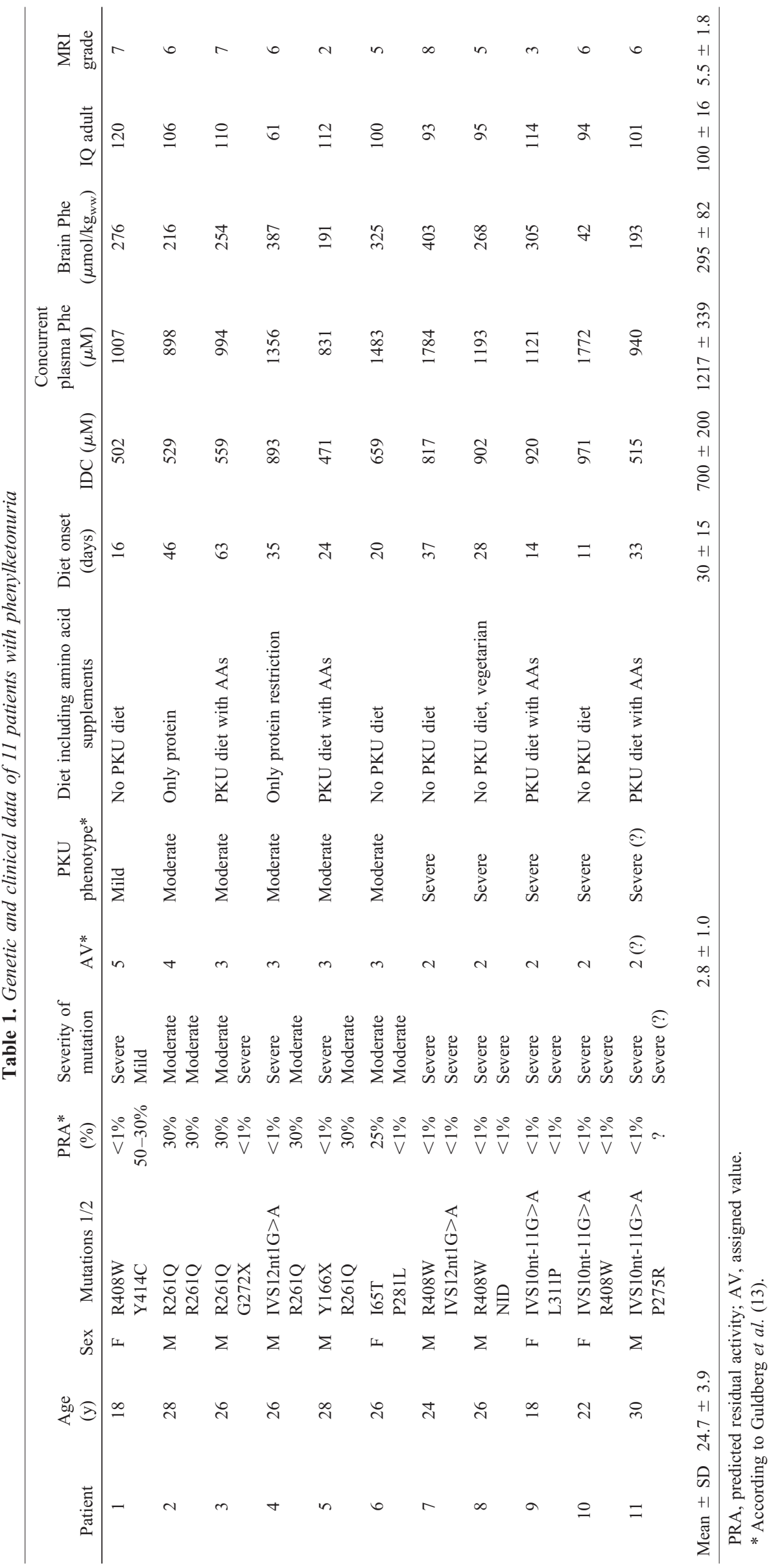


were placed according to the 10/20 system. Spectral analysis of EEG activity at rest was analyzed for occipital leads according to procedures described earlier (12). Because EEG spectra show systematic diurnal variations, comparison of EEG parameters was restricted to preload and $24 \mathrm{~h}$ postload measurements, which both were recorded during the morning hours.

Statistical analysis. Statistical analysis was carried out using the SAS statistical software package version 8.0 (SAS Institute, Cary, NC, U.S.A.) on Windows-NT. For testing for differences between groups, the Kruskal-Wallis test was used. Correlation analysis was done by calculating Spearman rank correlation coefficients. The $t$ test for repeated measurements was used for within-group retest comparisons during the Phe loading part of the study. $P<0.05$ was taken to be significant; $p$ values between 0.05 and 0.10 were reported as trends.

\section{RESULTS}

\section{Clinical Data}

Clinical data are summarized in Table 1. Most mutations were typical for European PKU patients. Five patients corresponded to severe PKU, four patients had a moderate type, and two patients had a mild or mild to moderate type (13). Other aspects of the PKU genotypes of this group have recently been discussed (15).

Concurrent plasma Phe values ranged between 799 and 1784 $\mu \mathrm{M}$, which is in the typical range for adult PKU patients (Table 1). Plasma and brain concentrations of Phe were closely associated $(\mathrm{r}=0.95, p<0.0001)$, as previously reported for these patients as part of a larger ${ }^{1} \mathrm{H}-\mathrm{MRS}$ study (15). Mean IQ in adult age was 100.5 (61-120). Neurologic status was normal except for mild tremor, which was present in two patients (2 and 6). Standard MRI in all 11 patients showed supra- and, less frequently, infratentorial nonspace-occupying white matter abnormalities.

\section{${ }^{31}$ P-MR Spectroscopy}

Comparison of PKU with control group under steady-state conditions. The cerebral ${ }^{31} \mathrm{P}$ MR spectrum of a typical PKU patient is presented in Figure 1, together with the best fitting model spectrum. In addition, the fitted spectrum was decomposed into three subspectra to demonstrate the contributions of the individual metabolites. The ${ }^{31} \mathrm{P}$ resonances can be attributed to nucleotide triphosphates, primarily ATP (with its subcomponents $\alpha$-, $\beta$-, and $\gamma$-ATP), PCr, phosphodiesters (PDE), phosphomonoesters (PME), and $\mathrm{P}_{\mathrm{i}}$. The apparent signal from $\alpha$-ATP has a shoulder that is attributed to NAD. Underlying these sharper resonances is a broad baseline signal that originates mostly from less mobile membrane-bound phospholipids (PL) and possibly to a smaller extent nucleic acids or other macromolecules (24). The steady-state tissue contents of these metabolites; the derived concentrations of ADP and $\mathrm{Mg}^{2+}$; and cerebral $\mathrm{pH}, \mathrm{PP}$, and $V / V_{\max }$ are listed in Table 2. Figure 2 contains the spectra of all PKU patients and control subjects; Figure 3 depicts the corresponding average spectra.

Concentrations of ATP, PCr, NAD, PME, and PDE, as well as $\mathrm{Mg}^{2+}$ and $\mathrm{pH}$ were indistinguishable for PKU patients and

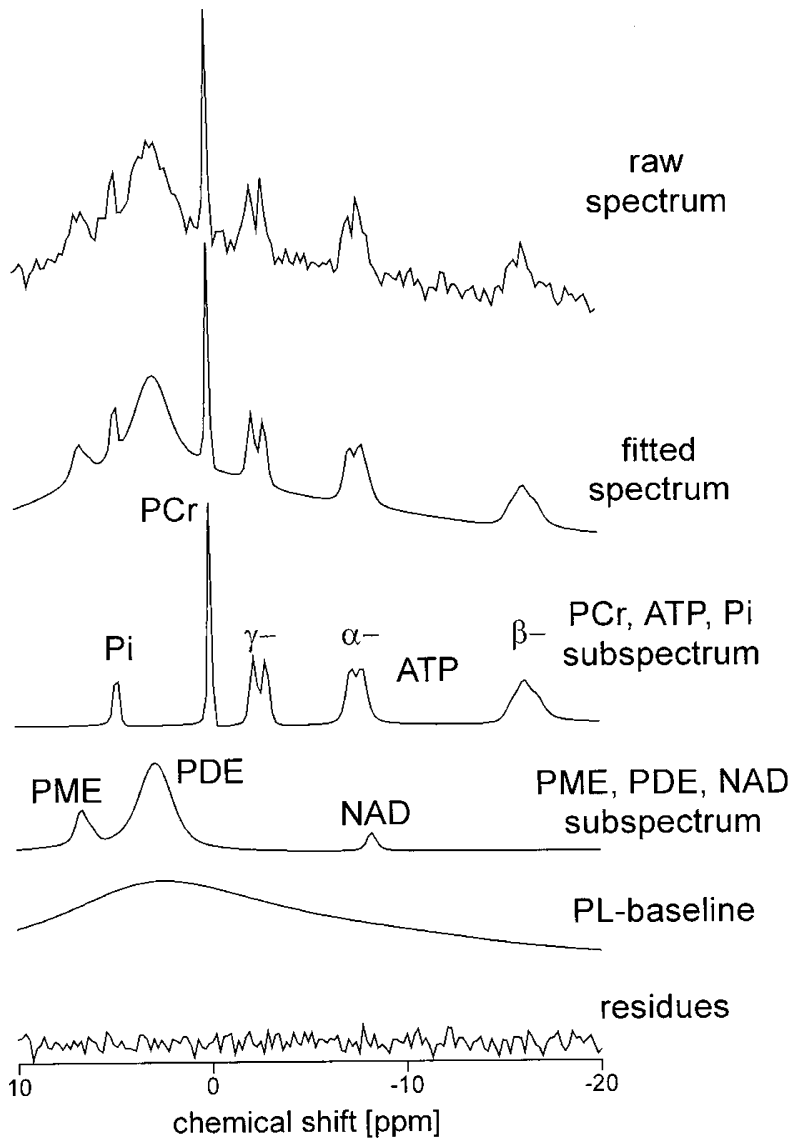

Figure 1. Cerebral ${ }^{31} \mathrm{P}-\mathrm{MR}$ spectrum from a 24-year-old male PKU patient with a plasma Phe level of $1784 \mu \mathrm{M}$. This figure demonstrates the quality of individual spectra and the data modeling procedure. The raw spectrum is the sum of four separately recorded ISIS spectra. Below, the sum of the four separate model fits is displayed. This fitted spectrum is divided into three subspectra to demonstrate the contributions of the individual metabolites. The last row is the difference between recorded and modeled spectra. The spectra are displayed after $4 \mathrm{~Hz}$ Gauss apodization and 0 order phasing.

Table 2. Steady-state results from quantitative ${ }^{31} P$-MRS in 11 adult $P K U$ patients and a control group ( $\mathrm{mmol} / \mathrm{kg}_{w w}$ )

\begin{tabular}{lcc}
\hline & $\begin{array}{c}\text { Control group } \\
(N=10 ; \text { mean } \pm \mathrm{SD})\end{array}$ & $\begin{array}{c}\text { PKU patients } \\
(N=11 ; \text { mean } \pm \mathrm{SD})\end{array}$ \\
\hline $\mathrm{PCr}$ & $2.72 \pm 0.11$ & $2.65 \pm 0.20$ \\
$\mathrm{ATP}$ & $2.41 \pm 0.15$ & $2.46 \pm 0.13$ \\
$\mathrm{ADP}$ & $0.019 \pm 0.001$ & $0.021 \pm 0.003 \dagger$ \\
$\mathrm{NAD}$ & $0.20 \pm 0.08$ & $0.16 \pm 0.10$ \\
$\mathrm{P}_{\mathrm{i}}^{*}$ & $0.92 \pm 0.09$ & $0.72 \pm 0.14 \dagger$ \\
$\mathrm{PDE}$ & $8.97 \pm 1.29$ & $8.83 \pm 1.44$ \\
$\mathrm{PME}$ & $1.75 \pm 0.29$ & $1.79 \pm 0.36$ \\
$\mathrm{PL} \mathrm{baseline}$ & $126.1 \pm 8.58$ & $115.6 \pm 8.88 \dagger$ \\
$\mathrm{Mg}$ & $0.18 \pm 0.03$ & $0.17 \pm 0.04$ \\
$\mathrm{pH}$ & $7.00 \pm 0.02$ & $7.01 \pm 0.02$ \\
$\mathrm{PP}(\mathrm{mmol} / \mathrm{kg})^{-1}$ & $138.5 \pm 10.9$ & $168.7 \pm 35.1 \dagger$ \\
$\mathrm{V} / \mathrm{V}_{\max }(\%)$ & $45.4 \pm 1.7$ & $46.3 \pm 2.7$ \\
\hline
\end{tabular}

* Corrected for $\mathrm{P}_{\mathrm{i}}$ in CSF.

Level of significance $\dagger p<0.05, \$ p<0.01$.

controls. In contrast, ADP was significantly elevated by $\sim 10 \%$ in the PKU patients. This difference corresponds roughly to the measurement variation for ADP expected for single subjects based on the fitting uncertainties in single spectra. Five of the 11 PKU patients $(1,6,7,8$, and 10) were on or above $2 \mathrm{SD}$ of 

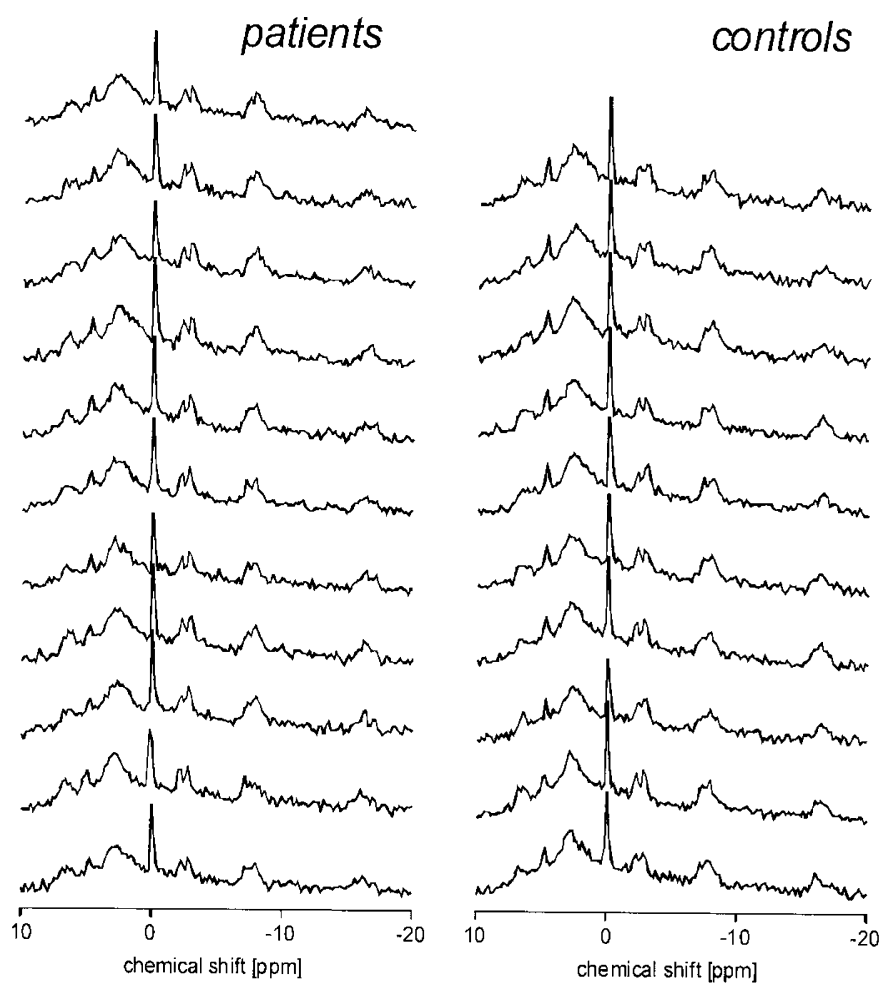

Figure 2. ${ }^{31} \mathrm{P}-\mathrm{MR}$ spectra of all PKU patients at steady state in comparison with healthy controls. The mean signal-to-noise ratio with respect to $\mathrm{PCr}$ is 44 with relatively little variation between spectra, because neither coil loading nor line widths or voxel size changed much between different investigations. The Cramer-Rao minimum variance bounds, which take prior knowledge into account and, hence, are the relevant error estimates for the fitting results, were slightly below 3\% for PCr, as well as ATP for each subject. They are somewhat smaller than the interindividual variations found for the control group (Table 2), which are codetermined by further fluctuations introduced by absolute quantitation procedures, exact placement of voxel, and true biologic variations.

the ADP control mean. $P_{i}$ was decreased by $\sim 20 \%$ in PKU. Six PKU patients $(1,2,3,4,7$, and 8$)$ had $P_{i}$ values that were $>2$ $\mathrm{SD}$ below the $\mathrm{P}_{\mathrm{i}}$ control mean. The baseline PL component was $\sim 8 \%$ lower in PKU compared with the controls.

ADP concentrations were correlated with plasma phenylalanine (Phe; $\mathrm{r}=0.65, p<0.05$ ). There was a trend for an association of ADP with brain Phe $(\mathrm{r}=0.55, p<0.1)$, as well as IDC $(\mathrm{r}=0.53, p<0.1)$. The PP was significantly negatively correlated with IDC $(\mathrm{r}=-0.62, p<0.05)$, whereas correlations with concurrent plasma $(\mathrm{r}=-0.50)$ and brain $(\mathrm{r}=$ -0.38 ) Phe concentrations were not significant. $V / V_{\max }$, which is usually $\sim 50 \%$ in normocapnia, was comparable for the control subjects and the PKU patients under steady-state conditions (Table 2). None of the parameters derived from ${ }^{31} \mathrm{P}$ MRS was associated with the patients' IQ.

Dynamic data during an oral Phe challenge. After the Phe load, plasma Phe concentrations increased steeply from preload values $(1073 \pm 315 ; 799-1465 \mu \mathrm{M}$ Phe) to a maximum $\sim 1 \mathrm{~h}$ postload and slowly decreased thereafter. Twenty-fourhour postload plasma Phe concentrations (1749 \pm 156 ; 1549 $1929 \mu \mathrm{M}$ Phe) were still substantially elevated in comparison with preload values. Concomitantly, Phe concentrations in

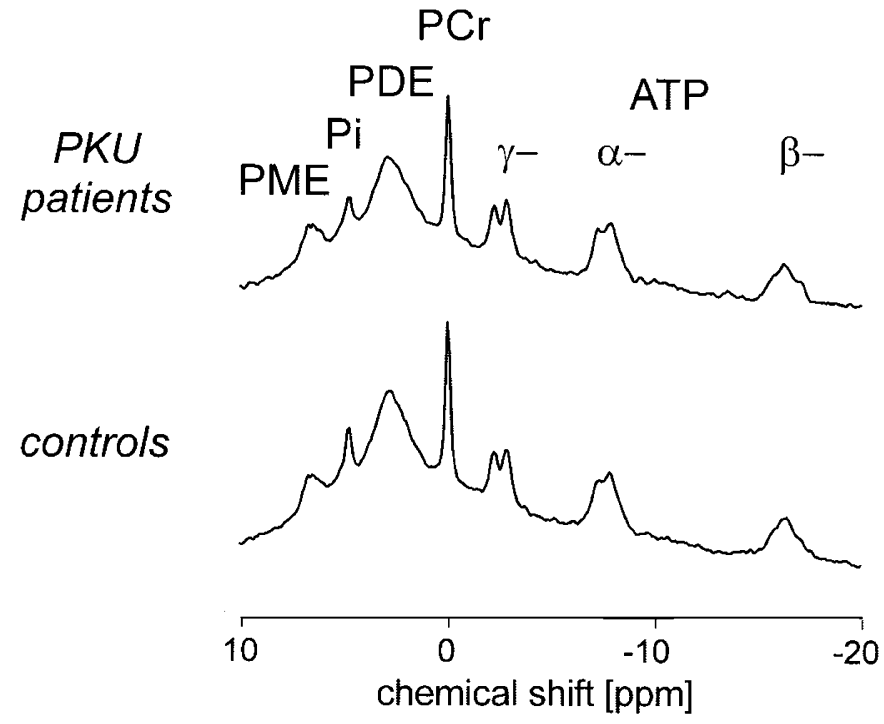

Figure 3. Averaged ${ }^{31} \mathrm{P}-\mathrm{MR}$ spectra of PKU patients in comparison with healthy controls. The averaged raw spectrum of 11 PKU patients at steady state is compared with the average control spectrum. The spectra reflect the changes in concentrations found by quantitative analysis only partly, because they are not corrected for coil loading and different line widths. However, the peak area of $\mathrm{P}_{\mathrm{i}}$, which was significantly reduced in quantitative analysis, is found to be reduced also in visual evaluation. The broad baseline component PL was reduced quantitatively in the PKU patients. This is also notable in the spectra. There are no obvious differences for ATP and PME.

brain tissue increased from baseline $180 \pm 140 \mu \mathrm{mol} / \mathrm{kg}_{\mathrm{ww}}$ to $420 \pm 70 \mu \mathrm{mol} / \mathrm{kg}_{\mathrm{ww}} 24 \mathrm{~h}$ postload.

Under the Phe load, PCr decreased in four of the five patients $(3,4,5$, and 11) and remained unchanged in the subject with lowest preload PCr (Fig. 4A). In addition, ATP decreased in the same four patients (Fig. 4B). Statistically, this yielded a trend for lower postload mean PCr and ATP concentrations (Table 3). Postload PCr values of the five PKU patients were significantly lower in comparison with the control mean $\left(\chi^{2}=4.3, p<0.05\right)$. ADP concentrations increased during the Phe load (Fig. 4C) in all five PKU patients, and postload ADP values were significantly higher in comparison with preload values and the control mean $\left(\chi^{2}=4.2, p<0.05\right)$. Postload $\mathrm{P}_{\mathrm{i}}$ was not significantly different from preload $P_{i}$ values, even though it had increased in four of five patients (Fig. 4D). PP, which was increased in comparison with the control group under steady-state conditions, decreased during the Phe load (Fig. 4E). Postload PP values were comparable to the control group $\left(\chi^{2}=0.02, \mathrm{~ns}\right)$. During Phe loading, $V / V_{\max }$ (Fig. $\left.4 \mathrm{~F}\right)$ increased significantly by $\sim 7 \%$. NAD, PME, PDE, and the membrane-bound $\mathrm{PL}$ compounds as well as $\mathrm{pH}$ and $\mathrm{Mg}^{2+}$ concentrations were not affected by Phe loading.

EEG results showed that whereas the individual profiles of the power spectra were reproduced, a shift of the dominant peak of background activity to lower frequency had occurred postload (example from a single subject in Fig. 5). An increase of $\theta$ activity was accompanied by a simultaneous decrease of $\alpha 2$ activity. There was a trend for a lower $\alpha / \theta$ quotient. Peak frequency and mean power frequency (MPF) decreased (Table 2). These changes were noted in all five patients. Visual evaluations of all EEG recordings revealed no abnormalities. The amount of MPF 

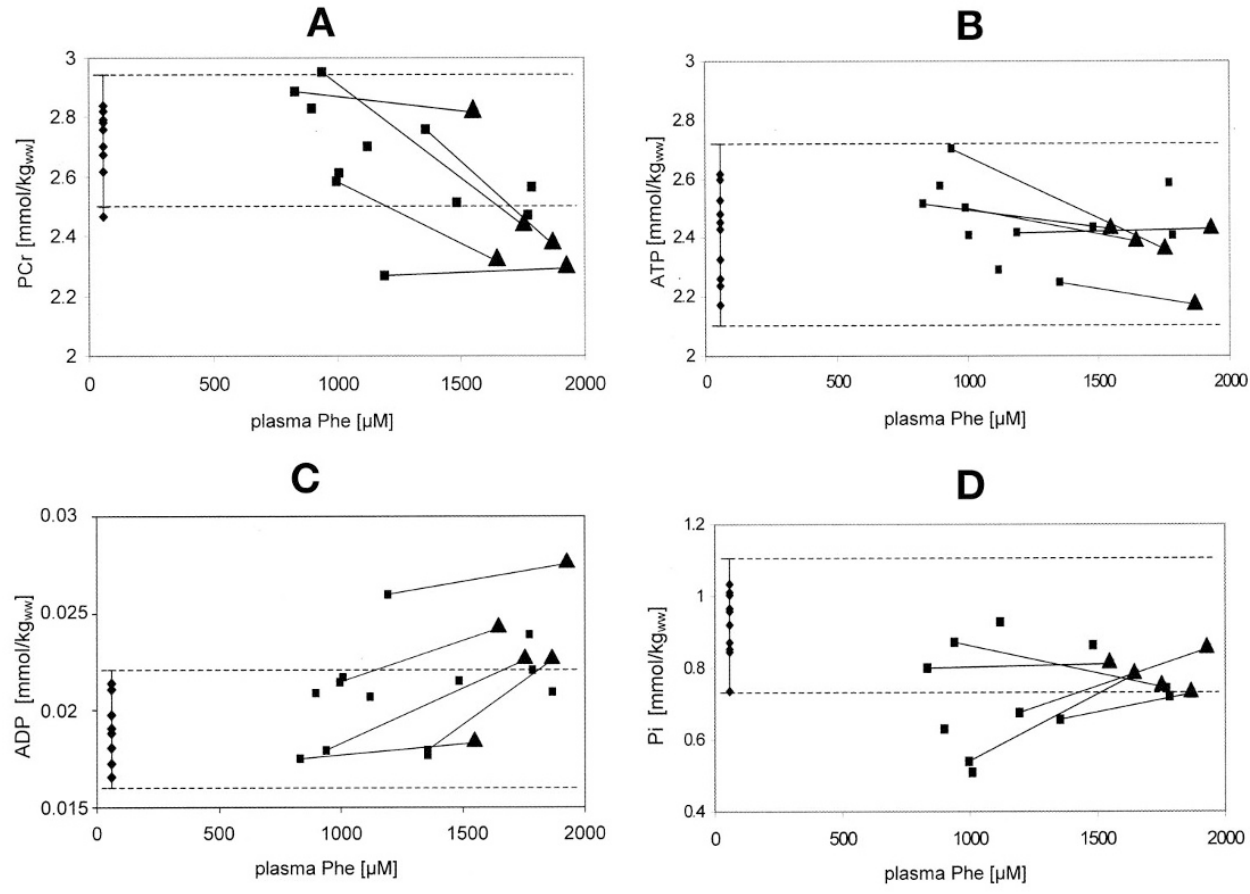

$\mathbf{E}$
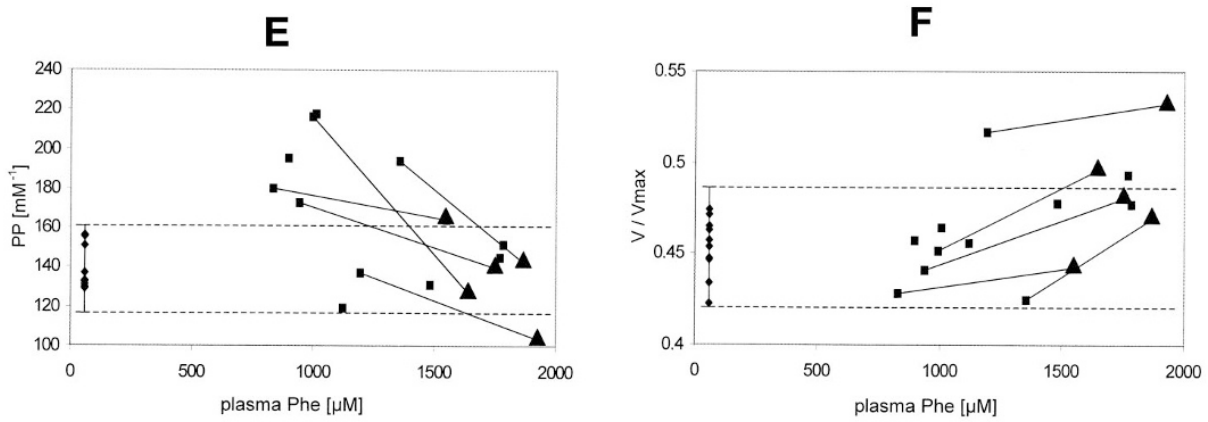

Figure 4. ${ }^{31} \mathrm{P}-\mathrm{MRS}$ data of PKU patients $(\boldsymbol{\square})$ and control subjects $(\bullet)$ plotted against the concurrent plasma level of Phe. In the control subjects, plasma Phe was set to $60 \mu \mathrm{M}$. Normal ranges ( $\pm 2 \mathrm{SD}$ ) are indicated in dotted lines. In five PKU patients, an oral load with $100 \mathrm{mg} / \mathrm{kg}$ body wt L-Phe was performed. Postload ${ }^{31} \mathrm{P}$-MRS results are given as triangles $(\mathbf{\Lambda})$. A, PCr showed a significant decrease postload. $B$, ATP, which was comparable to control values under steady-state conditions, showed a decreasing trend with Phe loading. $C$, ADP, which was already elevated during steady state, increased further under the Phe challenge. $D$, $\mathrm{P}_{\mathrm{i}}$ was lowered in comparison with control but showed no significant changes during Phe loading. $E$, PP was elevated at steady state but decreased concomitant to the acute rise in Phe concentration under the Phe load. $F$, The relative velocity of oxidative metabolism $\left(\mathrm{V} / \mathrm{V}_{\max }\right)$, which was comparable for PKU and control values but increased with Phe loading.

changes between preload and postload measurements $(\triangle \mathrm{MPF})$ was not associated with the amount of Phe increase from preload steady-state measurements to postload values $(\Delta \mathrm{Phe})$ in plasma $(\mathrm{r}$ $=0.15, \mathrm{~ns})$ or brain tissue $(\mathrm{r}=-0.45) . \Delta \mathrm{MPF}$ correlated significantly with the increase of cerebral ADP concentrations $(\Delta \mathrm{MPF} * \Delta \mathrm{ADP} \mathrm{r}=-0.93, p<0.05)$.

During the Phe load, blood glucose levels were above $4.4 \mathrm{mM}$, and standard laboratory evaluations (red and white blood cell counts, electrolytes, transaminases) remained in the normal range. After 10 days, Phe levels had always returned to preload values.

\section{DISCUSSION}

In this study, energy status of the brain of patients with PKU was investigated in vivo by ${ }^{31} \mathrm{P}-\mathrm{MRS}$. In general, ${ }^{31} \mathrm{P}-\mathrm{MRS}$ is an excellent technique to monitor cerebral energy metabolism in vivo. Moreover, it provides information on PL metabolism in the brain. Both aspects are important in understanding impaired brain development and function in PKU. In comparing quantitative ${ }^{31} \mathrm{P}-\mathrm{MRS}$ data of adult PKU patients and healthy controls, significant differences were found under steady-state conditions, thereby suggesting an influence of the specific biochemical properties of PKU on cerebral energy status.

The challenge of five PKU patients with high doses of oral L-Phe corroborated the impact of Phe on the balance of high-energy phosphorus metabolites. Changes in the phosphorus compounds were accompanied by slowing of EEG background activity, which has been found to be a specific sign of impaired brain function $(2,12)$.

Given the relatively small magnitude of the changes and the limited number of investigated subjects, one should keep alternative explanations in mind. In particular, it could be discussed if changes in compartment sizes or osmotic effects could induce the 
Table 3. ${ }^{31} P$-MRS and EEG findings before and $24 \mathrm{~h}$ after an oral load with L-Phe in 5 PKU patients (mean $\pm S D$ )

\begin{tabular}{|c|c|c|}
\hline & Preload $(N=5)$ & Postload $(N=5)$ \\
\hline \multicolumn{3}{|l|}{${ }^{31} \mathrm{P}-\mathrm{MRS}\left(\mathrm{mmol} / \mathrm{kg}_{\mathrm{ww}}\right)$} \\
\hline $\mathrm{PCr}$ & $2.69 \pm 0.27$ & $2.45 \pm 0.21 \dagger$ \\
\hline ATP & $2.48 \pm 0.16$ & $2.36 \pm 0.11 \dagger$ \\
\hline $\mathrm{ADP}$ & $0.020 \pm 0.004$ & $0.023 \pm 0.004 \ddagger$ \\
\hline NAD & $0.19 \pm 0.05$ & $0.16 \pm 0.07$ \\
\hline $\mathrm{P}_{\mathrm{i}}^{*}$ & $0.71 \pm 0.13$ & $0.78 \pm 0.05$ \\
\hline PDE & $8.82 \pm 1.69$ & $8.47 \pm 0.78$ \\
\hline PME & $1.63 \pm 0.33$ & $1.70 \pm 0.35$ \\
\hline PL baseline & $109.49 \pm 9.70$ & $110.78 \pm 15.70$ \\
\hline $\mathrm{Mg}^{2+}$ & $0.18 \pm 0.05$ & $0.19 \pm 0.02$ \\
\hline $\mathrm{pH}$ & $7.00 \pm 0.01$ & $7.00 \pm 0.02$ \\
\hline $\mathrm{PP}(\mathrm{mmol} / \mathrm{kg})^{-1}$ & $181.2 \pm 30.4$ & $135.1 \pm 23.6 t$ \\
\hline $\mathrm{V} / \mathrm{V}_{\max }(\%)$ & $45.3 \pm 3.7$ & $48.4 \pm 3.3 \ddagger$ \\
\hline \multicolumn{3}{|l|}{ EEG spectral parameters } \\
\hline EEG: $\theta$ band $[\%]$ & $20.0 \pm 11.5$ & $27.3 \pm 13.7 \pm$ \\
\hline EEG: $\alpha 1$ band [\%] & $43.4 \pm 20.0$ & $42.7 \pm 20.0$ \\
\hline EEG: $\alpha 2$ band [\%] & $15.2 \pm 5.0$ & $8.0 \pm 4.4 \S$ \\
\hline EEG: $\alpha / \theta$ ratio & $4.0 \pm 2.7$ & $2.4 \pm 1.5 \dagger$ \\
\hline EEG: PF [Hz] & $9.8 \pm 0.6$ & $9.1 \pm 0.4 \S$ \\
\hline EEG: MPF [Hz] & $9.1 \pm 0.6$ & $8.6 \pm 0.8 \S$ \\
\hline
\end{tabular}

* Corrected for $\mathrm{P}_{\mathrm{i}}$ in CSF.

Level of significance $\dagger p<0.1, \ddagger p<0.05, \S p<0.01$.

observed alterations. After the oral load, brain tissue concentrations of Phe increased from 180 to $420 \mu \mathrm{M} / \mathrm{kg}_{\mathrm{ww}}$, which is not sufficient to cause unspecific effects, such as disturbed balances of intra- and extracellular water or other aspects of cellular homeostasis. The elevation of ADP levels could be interpreted as being caused by decreased total creatine levels in PKU (Eq. 1). However, that no significant concentration changes have been reported for total creatine and $\mathrm{N}$-acetylaspartate $(3,25)$ and that the changes in Phe content are small render these interpretations implausible. In addition, the acute rise in ADP with Phe loading cannot be easily explained by lowered creatine levels. Thus, it is most likely that the observed changes in cerebral energy status and brain function are caused by specific effects of Phe.

Energy metabolism in PKU. Comparisons between PKU patients and controls showed that there are no significant group differences for the high-energy phosphate metabolites $\mathrm{PCr}$ and ATP. However, Phe loading yielded trends for decreasing ATP and $\mathrm{PCr}$ levels with increasing Phe concentrations (Fig. 4A). $\mathrm{ADP}$, which is calculated from $\mathrm{PCr}$, ATP, and $\mathrm{pH}$, was increased (as a result of additive nonsignificant but unidirectional trends in these three variables). An increase of ADP concentration, which is considered to be the major driving force for mitochondrial energy production, suggests that energy production, as well as consumption, could be increased in PKU. However, normal PCr and ATP levels at steady-state confirm that the system is compensated. In a decompensated state, e.g. in mitochondrial disease (26), $\mathrm{PCr}$ and PP are typically reduced, whereas $P_{i}$ is increased.

$\mathrm{P}_{\mathrm{i}}$ was found to be lower in PKU than in controls under steady-state conditions. It is presumed that the $\mathrm{P}_{\mathrm{i}}$ signal in ${ }^{31} \mathrm{P}$ MRS represents $<50 \%$ of the total intracellular levels, because $P_{i}$ that is bound to the mitochondrial inner membrane may not be mobile enough and thus is MR-invisible $(27,28)$. This suggests that there is less cerebral $\mathrm{P}_{\mathrm{i}}$ or that more of it is in a bound state. Lowered $\mathrm{P}_{\mathrm{i}}$ was already observed in an animal model of PKU
(29). In this study, brain tissue of hyperphenylalaninemic rats was investigated with ${ }^{31} \mathrm{P}-\mathrm{MRS}$ and biochemical and histologic methods. Decreased $\mathrm{P}_{\mathrm{i}}$ was one of the significant ${ }^{31} \mathrm{P}-\mathrm{MRS}$ findings, whereas PCr was normal. It could be speculated that an enhanced synthesis of $\mathrm{PCr}$ might be involved in the mechanisms responsible for low $P_{i}$ levels in PKU (9).

Additional evidence for involvement of cerebral energy metabolism in pathophysiological processes in PKU comes from other animal and in vitro studies that demonstrated that L-Phe itself, as well as its metabolites, inhibited brain energy metabolism $(4,5$, 30, 31). Inhibition of hexokinase [EC 2.7.1.1.] and possibly also pyruvate kinase [EC 2.7.1.40] activity was discussed as a major cause of these effects (32). Recently, new results corroborating our clinical findings have been reported. Inhibition of the mitochondrial chain and increased oxidative stress by elevated Phe concentrations were reported for rat brain $(33,34)$.

The link between acute impairments of brain function and imbalances of high-energy phosphates, as shown in this ${ }^{31} \mathrm{P}$ MRS study, adds a new aspect to the hitherto unresolved puzzle of Phe neurotoxicity. Interestingly, the amount of EEG changes as expressed by $\triangle \mathrm{MPF}$ correlated significantly with the amount of ADP increase in these five patients. However, as the number of subjects involved was low, this result requires confirmation. As a result of normal PAH activity, healthy controls show different kinetics after standardized oral L-Phe loading with steeply declining plasma Phe immediately after reaching peak concentrations. Thus, comparable investigations unfortunately cannot easily be performed in control subjects.

$P L$ components in ${ }^{31} P$-MRS. MRI studies on early-, late-, and untreated PKU patients show a high frequency of white matter abnormalities in neurologically normal patients. The nature of these white matter abnormalities remains unclear but could relate to mobile and membrane-bound PL, which constitute essential parts of cell membranes and myelin and which can partly be observed by ${ }^{31} \mathrm{P}-\mathrm{MRS}$.

The PME multicomponent comprises predominantly phosphoethanolamine and phosphocholine, as well as precursor and breakdown products of membrane PL. It is regarded as representing mainly the anabolic activity of PL (35). PDE consists of glycerol-3-phosphoethanolamine and -choline, as well as mobile PL, phosphorylized glycolipids, and glycoproteins. Thus, this peak represents relatively mobile PDE and at the same time metabolites involved in the catabolic pathway of membrane PL. The ${ }^{31} \mathrm{P}$ signals that are evaluated as broad PL baseline primarily originate from less mobile PL in membranes, but there is a smooth transition between PDE and PL baseline signals. The segregation between the two is method dependent. Although our study revealed no abnormalities in the PME and the narrow PDE compounds, it clearly showed a reduction of the broad baseline signal (Table 2). This is in accordance with observations made by ${ }^{31} \mathrm{P}$-MRS in hyperphenylalaninemic rats (29). In these animals, brain myelinogenesis was disturbed, because they had lower brain weights, cerebrosides, sulfatides, myelin basic protein, reduced cerebroside sulfotransferase, and 2'3'-cyclic nucleotide-3'-phosphohydrolase activities. Biochemical analysis revealed no changes in total proteins, lipids, PL, phosphatidylethanolamine, and phosphorylethanolamine. The baseline PL were not evaluated. 

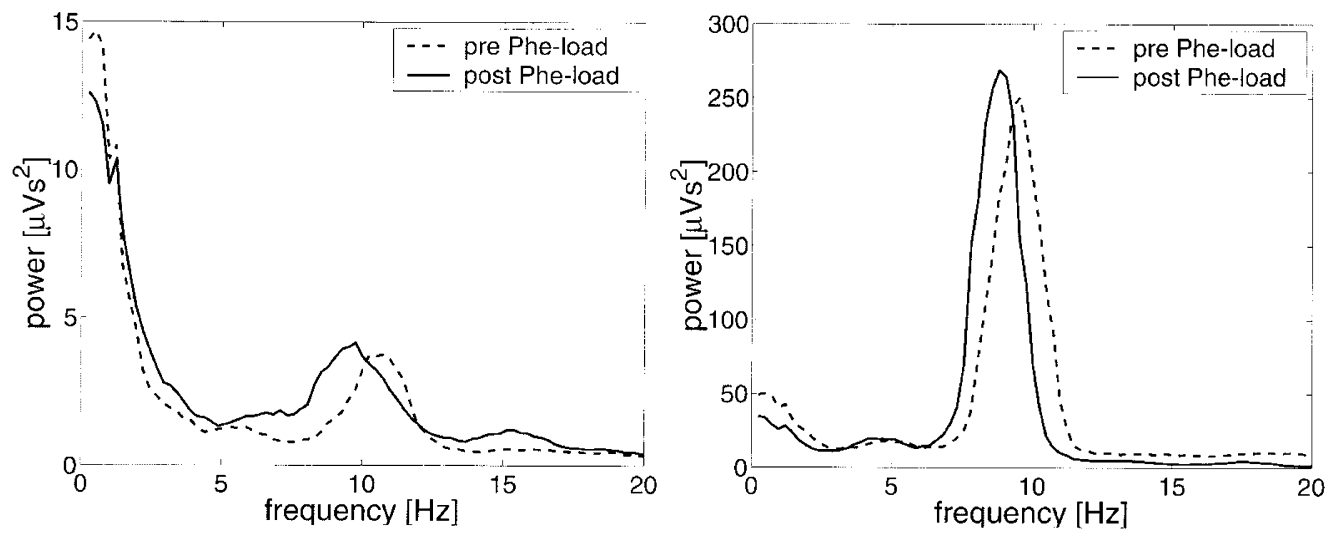

Figure 5. Power spectra (lead Oz) of EEG activity at rest derived from two adult PKU patients (left, patient 5; right, patient 11) before (- --) and $24 \mathrm{~h}$ after ( - ) an oral load with a single dose of $100 \mathrm{mg} / \mathrm{kg}$ body wt L-Phe. Whereas the individual profiles of the power spectra were reproduced under both conditions, the peak of the dominant background activity moved to lower frequency.

In our study, we observed neither lower PDE concentrations nor any correlation of PDE or PL with the amount of MRIvisible white matter changes in the PKU group. As the mobile part of the PDE decreases with increasing severity of demyelination (35), normal PDE in this study together with normal choline concentrations observed by means of ${ }^{1} \mathrm{H}$ MRS (3) contradicts demyelination in adults with PKU and high-signal white matter abnormalities.

\section{CONCLUSION}

In summary, in vivo ${ }^{31} \mathrm{P}-\mathrm{MRS}$ demonstrated changes of cerebral energy metabolism in adult PKU patients. Under steady-state conditions, the balance of energy production and consumption seemed to be undisturbed, and ATP concentrations were normal. Both further impairment of energy status and typical Phe-related changes in EEG background activity were observed with an acute rise of plasma and brain Phe, induced by an oral Phe challenge. Thus, acute Phe neurotoxicity may, at least partly, be attributed to imbalances of the high-energy phosphates. It remains unclear whether the impact of elevated Phe levels on cerebral energy metabolism also contributes to the severe disturbances of brain development in untreated PKU subjects. However, our first clinical results conjoined with the results of earlier and recent in vitro studies might serve to stimulate new attempts to investigate the role of energy metabolism in PKU pathophysiology.

\section{REFERENCES}

1. Scriver CR, Kaufman S 2001 Hyperphenylalaninemia: phenylalanine hydroxylase deficiency In: Scriver CR, Beaudet AL, Sly WS, Valle D (eds) The metabolic \& Molecular Bases of Inherited Disease, 8th Ed, Vol II. McGraw-Hill, New York, pp 1667-1724

2. Epstein CM, Trotter JF, Averbook A, Freeman S, Kutner MH, Elsas L 1989 EEG mean frequencies are sensitive indices of phenylalanine effects on normal brain. Electroencephalogr Clin Neurophysiol 72:133-139

3. Pietz J, Kreis R, Schmidt H, Meyding-Lamadé UK, Rupp A, Boesch C 2011996 Phenylketonuria: findings at MR imaging and localized in vivo $\mathrm{H}-1 \mathrm{MR}$ spectroscopy of the brain in patients with early treatment. Radiology 413-420

4. Glazer RI, Weber G 1971 The effects of phenylpyruvate and hyperphenylalaninemia on incorporation of $(6-3 \mathrm{H})$ glucose into macromolecules of slices of rat cerebral cortex. J Neurochem 18:2371-2382

5. Glazer RI, Weber G 1971 The effects of L-phenylalanine and phenylpyruvate on glycolysis in rat cerebral cortex. Brain Res 33:439-450

6. Land JM, Mowbray J, Clark JB 1976 Control of pyruvate and beta-hydroxybutyrate utilization in rat brain mitochondria and its relevance to phenylketonuria and maple syrup urine disease. J Neurochem 26:823-830

7. Miller AL, Hawkins RA, Veech RL 1973 Phenylketonuria: phenylalanine inhibits brain pyruvate kinase in vivo. Science 179:904-906

8. Kaufman S 1977 Phenylketonuria: biochemical mechanisms. In: Agranoff BW, Aprison MH (eds) Advances in Neurochemistry, Vol 2. Plenum Press, New York, pp 1-132

9. Kemp GJ, Radda GK 1994 Quantitative interpretation of bioenergetic data from 31P and $1 \mathrm{H}$ magnetic resonance spectroscopic studies of skeletal muscle: an analytical review. Magn Reson Q 10:43-63

10. Argov Z, Lofberg M, Arnold DL 2000 Insights into muscle diseases gained by phosphorus magnetic resonance spectroscopy. Muscle Nerve 23:1316-1334

11. Kemp GJ 2000 Non-invasive methods for studying brain energy metabolism: what they show and what it means. Dev Neurosci 22:418-428

12. Pietz J, Kreis R, Rupp A, Mayatepek E, Rating D, Boesch C, Bremer HJ 1999 Large neutral amino acids block phenylalanine transport into brain tissue in patients with phenylketonuria. J Clin Invest 103:1169-1178

13. Guldberg P, Rey F, Zschocke J, Romano V, Francois B, Michiels L, Ullrich K, Hoffmann GF, Burgard P, Schmidt H, Meli C, Riva E, Dianzani I, Ponzone A, Rey J, Guttler F 1998 A European multicenter study of phenylalanine hydroxylase deficiency: classification of 105 mutations and a general system for genotype-based prediction of metabolic phenotype. Am J Hum Genet 63:71-79

14. Kreis R, Pietz J, Penzien J, Herschkowitz N, Boesch C 1995 Identification and quantitation of phenylalanine in the brain of patients with phenylketonuria by means of in vivo ${ }^{1} \mathrm{H}$ magnetic resonance spectroscopy. J Magn Reson B 107:242-251

15. Rupp A, Kreis R, Zschocke J, Slotboom J, Boesch C, Rating D, Pietz J 2001 Variability of blood-brain ratios of phenylalanine in typical patients with phenylketonuria. J Cereb Blood Flow Metab 21:276-284

16. Lawry TJ, Karczmar GS, Weiner MW, Matson GB 1989 Computer simulation of MRS localization techniques: an analysis of ISIS. Magn Reson Med 9:299-314

17. Kreis R, Slotboom J, Pietz J, Jung B, Boesch C 2001 Quantitation of localized ${ }^{31} \mathrm{P}$ magnetic resonance spectra based on the reciprocity principle. J Magn Reson 149:245-250

18. Petroff OA, Prichard JW, Behar KL, Alger JR, den Hollander JA, Shulman RG 1985 Cerebral intracellular $\mathrm{pH}$ by $31 \mathrm{P}$ nuclear magnetic resonance spectroscopy. Neurology 35:781-788

19. Iotti S, Frassineti C, Alderighi L, Sabatini A, Vacca A, Barbiroli B 1996 In vivo assessment of free magnesium concentration in human brain by 31P-MRS. A new calibration curve based on a mathematical algorithm. NMR Biomed 9:24-32

20. Kemp GJ, Roussel M, Bendahan B, Le Fur Y, Cozzone PJ 2001 Interrelations of ATP synthesis and proton handling in ischaemic exercise studied by ${ }^{31} \mathrm{P}$ magnetic resonance spectroscopy. J Physiol 535:901-928

21. Veech RL, Lawson JW, Cornell NW, Krebs HA 1979 Cytosolic phosphorylation potential. J Biol Chem 254:6538-6547

22. Kreis R 1997 Quantitative localized ${ }^{1} \mathrm{H}-\mathrm{MR}$ spectroscopy for clinical use. Prog NMR Spectroscopy 31:155-195

23. Nioka S, Chance B, Hilberman M, Subramanian HV, Leigh Jr JS, Veech RL, Forster RE 1978 Relationship between intracellular $\mathrm{pH}$ and energy metabolism in dog brain as measured by 31P-NMR. J Appl Physiol 62:2094-2102

24. Murphy EJ, Rajagopalan B, Brindle KM, Radda GK 1989 Phospholipid bilayer contribution to 31P NMR spectra in vivo. Magn Reson Med 12:282-289

25. Dezortova M, Hajek M, Tintera J, Hejcmanova L, Sykova E 2001 MR in phenylketonuria-related brain lesions. Acta Radiol 42:459-466

26. Lodi R, Montagna P, Cortelli P, Iotti S, Cevoli S, Carelli V, Barbiroli B 2000 'Secondary' 4216/ND1 and 13708/ND5 Leber's hereditary optic neuropathy mitochondrial DNA mutations do not further impair in vivo mitochondrial oxidative metabolism when associated with the 11778/ND4 mitochondrial DNA mutation. Brain 123:1896-1902 
27. Iles RA, Stevens AN, Griffiths JR, Morris PG 1985 Phosphorylation status of liver by 31P-n.m.r. spectroscopy, and its implications for metabolic control. Biochem J 229:141-151

28. Garlick PB, Townsend RM 1992 NMR visibility of Pi in perfused rat hearts is affected by changes in substrate and contractility. Am J Physiol 263:H497-H502

29. Burri R, Matthieu JM, Vandevelde M, Lazeyras F, Posse S, Herschkowitz N 1990 Brain damage and recovery in hyperphenylalaninemic rats. Dev Neurosci 12:116-125

30. Granett SE, Wells WW 1972 Energy metabolism in the brains of L-phenylalaninetreated chicks. J Neurochem 19:1089-1098

31. Patel MS, Owen OE 1976 Effect of hyperphenylalaninaemia on lipid synthesis from ketone bodies by rat brain. Biochem J 154:319-325
32. Gimenez C, Valdivieso F, Mayor F 1974 Glycolysis in the brain and liver of rats with experimentally induced phenylketonuria. Biochem Med 11:81-86

33. Rech VC, Feksa LR, Dutra-Filho CS, Wyse AT, Wajner M, Wannmacher CM 2002 Inhibition of the mitochondrial respiratory chain by phenylalanine in rat cerebral cortex. Neurochem Res 27:353-357

34. Kienzle Hagen ME, Pederzolli CD, Sgaravatti AM, Bridi R, Wajner M, Wannmacher CM, Wyse AT, Dutra-Filho CS 2002 Experimental hyperphenylalaninemia provokes oxidative stress in rat brain. Biochim Biophys Acta 1586:344-352

35. Van der Knaap MS, van der Grond J, Luyten PR, den Hollander JA, Nauta JJ, Valk J $19921 \mathrm{H}$ and 31P magnetic resonance spectroscopy of the brain in degenerative cerebral disorders. Ann Neurol 31:202-211 